\title{
Consideraciones sobre el lugar: la regla y el modelo. De Igueldo a Zabalaga / Igeldotik Zabalagara
}

\author{
Ruminations on place: the rule and the model \\ (in Eduardo Chillida). Igeldotik Zabalagara
}

\author{
José Vela Castillo
}

IE University

jose.vela@ie.edu

\section{Resumen}

Este texto busca aproximarse a la obra escultórica de Eduardo Chillida desde un doble presupuesto. De una parte, se afirma que la escultura de Chillida construye lugares, lo que se argumenta explorando el significado de la palabra lugar y confrontándolo al más genérico de la palabra espacio. De otra, se propone que existe una íntima relación entre los conceptos de regla, modelo y paradigma y la propia escultura como construcción singular. La conclusión viene a ser que cada escultura de Chillida, especialmente aquellas en lugares abiertos como el Peine del viento o las que se encuentran en Chillida-Leku (pero no solo), se proponen como un cierto paradigma que, en cada caso, da lugar al lugar.

Palabras clave: Lugar, espacio, regla, modelo, paradigma

\begin{abstract}
The present text approaches the work of sculptor Eduardo Chillida from a two folded point of view. On one hand, it states that the sculpture of Chillida builds places, which is argued through the exploration of the meaning of words
\end{abstract}


place and space. On the other hand, it points to the close relationship that can be found between the concepts of rule, model and paradigm and the singular work of sculpture. Both threads lead to the final conclusion: the sculptures of Chillida, especially the ones in open spaces like the Peine del viento or those in Chillida-Leku, propose themselves as a paradigm that, in each particular situation, give place to the place.

Key words: Place, space, rule, model, paradigm

\section{Consideraciones sobre el espacio y el lugar}

Atacar, como quien anuncia ${ }^{1}$ su ley y su trampa, como un pianista (¿Arrau? ¿Zimerman?) attaca las primeras notas de la Sonata en si menor de Franz Liszt - como si el sonido brotase de las teclas no al pulsarlas, sino al levantar los dedos de ellas-, como quien se presenta sin anunciar y dice: la escultura de Eduardo Chillida es una escultura del lugar.

Pero... ¿en el lugar? ¿Con el lugar? ¿En qué lugar?

No, no... la escultura de Chillida da lugar al lugar, promueve o propone, muestra y señala, separa, delinea, grafía el lugar. No en un lugar, en realidad en cualquier lugar, sino como lugar. Su obra construye lugares -espacio/lugar como topós-, formaliza relaciones espacio-temporales -fenomenológicas-, extrae relaciones perceptivas, expone relaciones materiales y de esta forma hace aparecer una cierta verdad en su lugar: no en otro sino en el suyo, ahí, $D a$. Sus esculturas proponen en cada caso una regla y un modelo que, en su eficacia paradigmática, en su expuesta materialidad, en su singular iterabilidad dan lugar al lugar. A la verdad del lugar.

Enseguida se habrá reconocido la alusión a Martin Heidegger, la referencia a una forma de la verdad como desocultamiento ${ }^{2}$, como revelación (en el sentido de des-velamiento, aletheia), como forma -aparente- de la visibilidad en general (pero en este sentido como forma de la percepción: porque en realidad no se trata tanto del sentido de la vista como del sentido -y de los sentidos- en general, del traer a delante de nosotros levantando el/un velo, y esto no implica solo a la vista). Por tanto, del ver, sí, pero también y necesariamente en el caso de la escultura de Chillida del tocar, y del oír y del oler -el aroma como antici-

\footnotetext{
${ }^{1}$ ¿Enuncia?

2 Heidegger M., «La pregunta por la técnica», en Conferencias y artículos, Barcelona, Ediciones del Serbal, 1994, p. 15.
} 
pación de lo que ha de venir-, incluso del gustar o degustar, del paladear y el morder: dice Chillida,

"Los dientes y el oído saben ya, casi antes que la cabeza"3.

No es una afirmación nueva la de decir que la escultura de Eduardo Chillida trae a la presencia algo que antes no estaba, que no se daba, que ni siquiera se daba en la mente del escultor, como el propio Chillida se apresura a recordar en tantos sitios, por ejemplo:

"Yo conozco mi obra desde el comienzo, pero no sé cómo es"”. Y:

No se trata, no puede tratarse de "representar" de una manera más o menos perfecta e incluso personal lo aparente, lo conocido por todos, sino de penetrar "presentar" y hacer luz donde estaba oscuros.

No es nuevo tampoco decir que el arte en general "hace visible", que efectúa una cierta actualización (expresión problemática) o puesta en obra y que en ese proceso, que es técnico (y esto es importante), abre un nuevo horizonte. La escultura de Eduardo Chillida hace esto con precisión, con una precisión técnica y a la vez artesanal, con una cualidad ejemplar que nos conquista.

No será del todo nueva, por tanto, la propuesta que aquí hago: que eso que es la escultura de Eduardo Chillida, eso que desvela un algo que es un lugar, se propone y se construye como un modelo, sigue a la vez que inaugura una regla (acaso la del lugar), produce, físicamente, un paradigma, a la vez inimitable y ejemplar. Su escultura genera un esquema formal de organización del lugar en la forma de un ejemplo, del ejemplo, de los ejemplos pues son siempre varios, del ejemplo construido, que, como gran pregunta, responde del lugar como quien da fe notarial y lo muestra en su verdad (si es que esto no es lo mismo).

Pero antes de continuar, veamos qué entendemos por espacio y lugar en el contexto de esta exposición.

El espacio suele identificarse comúnmente con el espacio abstracto matemático-geométrico, con una cierta exterioridad (recuerdo, desde luego, de la res extensa cartesiana), con el ámbito en el que trabaja la tecnociencia, y con una generalidad y universalidad que, de hecho, lo hace imperceptible para la singularidad de los sentidos. Es ésta, desde luego, una forma de concebir el espacio que, desarrollada en la cultura occidental a partir del Renacimiento,

${ }^{3}$ Chillida, E., Escritos, Madrid, La fábrica-Museo Chillida-Leku, 2005, p. 25.

${ }^{4}$ Ibidem, p. 71.

${ }^{5}$ Ibidem, p. 71.

${ }^{6}$ La expresión es de Paul Klee y dice: "El arte no reproduce lo visible; vuelve visible". 
ha permitido el actual predominio de la técnica sobre cualquier otra consideración.

Sin embargo, el espacio con el que trabaja Chillida parece responder mejor a la palabra lugar que a la palabra espacio entendida de la manera arriba esbozada (si bien es cierto que Chillida emplea preferentemente el término espacio para referirse a él). A diferencia del espacio abstracto, el término lugar tendría que ver con el concepto de emplazamiento, con el pensamiento de que las cosas no están en cualquier sitio (y por lo tanto en ninguno) sino en un sitio determinado, y por lo tanto con un medio que no es homogéneo ni universal, sino discontinuo y particular. El espacio así concebido es también el espacio percibido, que afecta a los sentidos y es afectado él mismo por los sentidos. Un espacio que no existe de antes, sino que solo se muestra en su particularidad y en su aparecer, es decir, después.

Es un espacio también técnico en el sentido de que se le da forma, se produce de forma técnica, pero no desde el punto de vista del dominio tecnocientífico, sino desde el punto de vista, ya apuntado, de la verdad (de nuevo nos remitimos al Heidegger de «La pregunta por la técnica»).

Además, este espacio está poblado siempre de materia, es un espacio en el que no hay vacío o lo hay solo como materia de distinta-menor-densidad. Estamos ante un espacio que responde siempre a la gravedad, incluso aunque "parezca vacío", en el que la escultura trabaja tanto con la materia como con el "aire", que es así simplemente materia más ligera, pero que se somete a las mismas normas físicas que ésta. Las obras denominadas Gravitaciones dan buena cuenta de ello, por ejemplo.

Por otra parte, se trata de un espacio preñado de tiempo, interrumpido de tiempo, definido siempre mediante una relación variable pero ineludible entre ambos. Para Chillida espacio y tiempo se anudan en la forma de la velocidad'. Dice Chillida:

El espacio y la materia no están tan distantes el uno del otro, quizás los separa una diferencia de velocidad. La materia sería un espacio más lento o el espacio una materia rápida ${ }^{8}$.

Además, el espacio como lugar, el espacio/lugar de Chillida, es necesariamente un espacio limitado, delimitado, trazado y deslindado, trabajado por la traza de una línea, por una línea que dibuja: dirá Chillida,

\footnotetext{
${ }^{7}$ No olvidemos que velocidad=espacio/tiempo.

${ }^{8}$ Chillida 2005, op.cit. (nota 3), p. 55.
} 
En una línea el mundo se une, con una línea el mundo se divide, dibujar es hermoso y tremendo?.

Una línea que en el dibujo, en la incisión, en el trazado necesario de un límite, en la densidad del grafito de una línea o en la pulida arista de un bloque de piedra o un tocho de acero, al menos dos mundos separa. En el dibujo, en la incisión del dibujo se da contorno a las formas, se da forma a las cosas. Pero esta línea, este corte que une y separa, es decir que permite, al separar, que aparezca el sentido y que permite, precisamente en el trazo de la línea que se reúnan, se toquen, se palpen esas formas que se habían separado, ese grafo, cuando se hace dibujo en el espacio tridimensional, se hace escultura.

Este espacio entonces se mediría de otra manera que con la matemática o incluso que con la geometría (recordemos la aversión de Chillida por el ángulo exacto de $90^{\circ}$, el ángulo "recto" que no sería sino el ángulo inco-recto y su preferencia por los ángulos imperfectos que encontramos en el corto abanico de unos cinco grados arriba o abajo ${ }^{10}$ ). Citemos al escultor:

Lugar implica dimensión y límites. Pero el punto, lugar por excelencia, no tiene dimensión ni límites ${ }^{11}$.

\section{Y también}

Ocupar un lugar y no tener medida, ¿no será esto el espacio? ${ }^{12}$.

Y es que, como vemos, para Chillida la cuestión de la medida está íntimamente ligada a la de la geometría y a la del lugar. Se vale aquí de la paradoja de la geometría euclidiana, de acuerdo a la cual el plano tiene (o existe en) dos dimensiones, la línea una dimensión, y el punto, su núcleo fundacional, no tendría dimensión (es, pues, adimensional). De esta manera, la imposibilidad dimensional lo que hace es abrir el espacio a un más allá de la geometría y el número: a la percepción pero también a la construcción. La medida se independiza del número sin perder por ello nada de su exactitud, y se materializa como espacio en las esculturas, que se convierten entonces en instrumentos de medida y regulación. Pues, ¿no son acaso las esculturas de Chillida "reglas" de medida del espacio, prescripciones y deducciones que delimitan y pautan el

\footnotetext{
${ }^{9}$ Ibidem, p. 103.

${ }^{10}$ Ibidem, p. 105.

${ }^{11}$ Ibidem, p. 62.

${ }^{12}$ Ibidem, p. 64.
} 
espacio? ¿No se producen como modelos que proponen reglas, particulares en cada caso, de medida? Al igual que una regla física, que un escalímetro, que un compás o un calibre, sus obras son instrumento de medida tanto como encarnación de la regla misma, patrón formal modelado.

Finalmente, y volviendo a la cuestión del lugar, afirmaríamos con Heidegger (en "El arte y el espacio") que "tendríamos que aprender a reconocer que las cosas mismas son los lugares"13. Solo que no cualquier cosa es o puede ser un lugar, solamente lo podrían ser determinadas cosas, como las construcciones (ya se sabe, los puentes ${ }^{14}$ ) o las obras de arte. En este sentido el espacio/lugar no es algo previo al aparecer en él la escultura, sino que aparecen ambos conjuntamente. La producción de este espacio/lugar es la producción artística, y ésta queda propuesta como una forma ejemplar. La propuesta de Chillida es clara, entonces. Su escultura, siguiendo el modelo de Heidegger, se definiría como la "acción de corporeizar la verdad del ser en la obra, que instaura lugares" ${ }^{\prime 15}$.

Pero, ¿cómo se configuran sus esculturas? ¿Qué reglas siguen? ¿Qué modelo? ¿Por qué, más bien, regla y modelo explican, doblan y desdoblan su trabajo?

Retomemos, pues, la cuestión enunciada en el título.

\section{La regla y el modelo}

Se ha mencionado que la escultura de Chillida tiene una condición paradigmática, o por mejor decir, que construye en cada caso, en cada ejemplo material, un cierto paradigma.

Su forma de ser como lugar se daría entonces en la forma del paradigma: regla y modelo a la vez.

Intentemos aclarar este punto.

Regla y modelo parecen, a primera vista, imponer dos formas de la acción, o de la intervención sobre el lugar, que implican una previsión, un cálculo, un programa previo. Justo aquello que Chillida nos dice que no hay, porque,

¿No es el programar una manera de quitar al presente su más alta misión? ${ }^{16}$

${ }^{13}$ Heidegger M., «El arte y el espacio» en Heidegger M., Observaciones relativas al arte-la plástica-el espacio. El arte y el espacio, Pamplona, Cátedra Jorge Oteiza-Universidad pública de Navarra, 2003, p. 131.

${ }^{14}$ Heidegger M., «Construir, habitar, pensar», en Heidegger 1994, op.cit. (nota 2), p. 133.

${ }^{15}$ Heidegger 2003, op.cit. (nota 13), p. 137.

${ }^{16}$ Chillida 2005, op.cit. (nota 3), p. 17. 
Sin embargo, regla y modelo pueden ser aproximadas desde otro punto de vista. Tanto la regla como, sobre todo, el modelo, resultan estar cogidas dentro de la lógica ambigua del ejemplo, de la ejemplaridad y del paradigma.

Veamos ahora cómo aproximarnos a esta cuestión de la regla y el modelo de forma productiva.

Regla en principio parece referirse a una serie de pautas, de determinaciones a priori; por ejemplo, ateniéndonos al Diccionario de la Real Academia, una de sus acepciones (en concreto la novena) dice que regla es "pauta de la escritura" ${ }^{17}$. Pauta, por su parte, se define como "instrumento o aparato para rayar el papel en blanco" y a continuación como "raya o conjunto de rayas hechas con este instrumento", también como "instrumento o norma que sirve para gobernarse en la ejecución de algo". Esto nos sugiere varias posible relaciones, una de ellas musical, que permiten explorar el papel de la regla.

Volvamos la vista, pues, al papel pautado o pentagrama que regula la notación musical, y abramos un paréntesis. En la notación musical común el sentido de las cosas, la dirección y el movimiento de la música son necesariamente referidos a la posición de las notas dentro del pentagrama, a las relaciones que se establecen entre ellas y que el pentagrama, la pauta que subyace, no engendra sino que se limita a poner de manifiesto, a facilitar su reconocimiento. La regla, la pauta, no impone la música, pero establece el campo genérico de relaciones en que ésta puede aparecer y desarrollarse con sentido. Es importante señalar que, como toda notación, la notación musical no puede reproducir con total fidelidad el ideal de una música o la reproducción exacta de una determinada interpretación. De ahí es entonces, precisamente, que se hace necesaria la interpretación, y ahí es donde surge, además, la libertad. La regla o pauta general que establece la notación (y con ella todas sus normas asociadas en el largo devenir de la música occidental), la partitura, se actualiza en cada momento en que se interpreta (o en que se lee por quien sabe hacerlo).

De esta manera, cada interpretación musical concreta a partir de la escritura propone, o se propone como un modelo, como un ejemplo a seguir en la comprensión de tal o cual pieza; actualiza, modificando la regla escrita, la relación entre espacio y tiempo que establece el pentagrama para la materia sonora (vibración de la materia: velocidad del espacio). La escritura de la música queda sujeta, por otra parte, a un conjunto de reglas (armonía, contrapunto) que se actualizan en cada composición musical y que de nuevo se actualizan en cada interpretación musical. De modo que es en las propias obras musicales (en su doble condición escrita e interpretada) donde aparecen los principios de

${ }^{17}$ Diccionario de la lengua española, 22a edición (DRALE). 
la composición (tonalidad, armonía, contrapunto), y donde adquieren su condición de modelo.

El excurso musical quizás ha sido un poco largo, pero dada la cercanía de la escultura de Chillida a la música, y dada la percepción que no podemos sino llamar sinéstésica del escultor (por ejemplo: "La primera vez que entré en Santa Sofía, en Estambul, tuve una visión tremenda de espacio musical... Tenía la impresión de estar entrando en los pulmones de Juan Sebastián

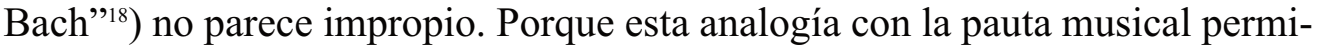
te extraer algunos principios que se dan en la escultura de Chillida: la pauta o norma como sistema de relaciones, la actualización constante de la pauta en cada escultura particular, la reactualización que se da en cada contemplador de ella, la condición de ejemplo por tanto, "tocado" (como al tocar un instrumento musical siguiendo una partitura) en un instante singular pero propuesto a la vez como universal.

Por otra parte, y seguimos con las acepciones del Diccionario de la Real Academia, regla es también el "conjunto de preceptos fundamentales que debe observar una orden religiosa”, y esto nos da una pauta más a explorar. Porque el origen de la regla, la regula, como bien expone Giorgio Agamben en Signatura Rerum ${ }^{19}$, no dice sino el modo de vida de los monjes en un determinado monasterio y en un determinado momento, y viene en su origen a ser la imitación, el seguimiento del modo de vida del fundador, que se identifica como ejemplo en la práctica a seguir, y que en última instancia remitiría a los Evangelios y a la vida de Jesús. Según esta interpretación, la regla monástica tendría una condición paradigmática, de modo que, concluye Agamben, "el paradigma implica un movimiento que va de la singularidad a la singularidad y que, sin salir de ésta, transforma cada caso singular en ejemplar de una regla general que nunca puede formularse a priori”20. Al igual que la regla monástica, la regla que expone Eduardo Chillida en cada una de sus esculturas tiene esta condición de no existir fuera de una práctica (la regla aparece en el monasterio como algo escrito mucho después de que se haya codificado en su pauta cotidiana), de anteceder a su propia escritura, de no poderse deducir a priori sino darse en la serie de las propias esculturas o en ellas de modo individual. Esta regla puede irse precisando, y de hecho lo hace a través del tiempo en las distintas esculturas que siguen un mismo nombre o a través del lugar en sucesivas intervenciones (así al considerar las diferentes esculturas en el espa-

${ }^{18}$ Chillida 2005, op.cit. (nota 3), p. 26.

${ }^{19}$ Agamben, G., Signatura Rerum. Sobre el método, Barcelona, Anagrama, 2010, p. 28.

${ }^{20}$ Ibidem, p. 29. 
cio de la ciudad de San Sebastián) sobre un mismo espacio. Pero nunca se puede enunciar como una regla a priori independiente de su darse en la práctica real.

Esta última forma de entender la regla nos aproxima a la cuestión del modelo. La regla parece poco a poco dejar de ser la encarnación de unos ciertos principios inmutables, representación del "orden y concierto invariable que guardan las cosas naturales" (de nuevo el DRAE), la puesta por escrito de unas normas a priori, acaso trascendentes, que regulan todo aquello que hay, para acercarse a la idea de una construcción que se da en la práctica, en el movimiento del hacer, en la modelización física sin por ello perder su condición ejemplar. Porque modelo implica construcción (no confundir, sin embargo, con el modelado tradicional de la escultura, práctica totalmente opuesta al trabajo de Chillida sobre el material).

El modelo implica, reúne en sí mismo, la construcción a la vez de un ejemplo particular de regla y de una regla general que podría aplicarse con aparente independencia. El modelo parece encarnar un algo a imitar ${ }^{21}$, un ejemplo que debe ser doblado, copiado, pero sin dejar de proponer, por sí mismo, una singularidad propia ${ }^{22}$. El modelo es entonces un particular, una singularidad que no se relacionaría, sin embargo, con un conjunto mayor que forme una totalidad, parte de un todo superior, sino que propone una relación de partes entre partes, de singularidades entre singularidades. No hay una regla que una todas las esculturas de Chillida, no se perfecciona en cada una: se da a la vez en todas como un particular, distinto en cada caso, en cada modelo. Cogidas todas en un mismo aroma, componen sin embargo partituras distintas. Regla y modelo se unen así en la construcción del paradigma.

El modelo como paradigma, de esta manera, se entiende como un objeto que propone a la vez una regla general y una singularidad propia. Y esta es la propuesta de la escultura de Chillida. Cada una de ellas, de sus obras, en su singularidad, propone un lugar propio, desvela un lugar, lo hace visible allí donde se instale. Y cada una de ellas, precisamente en su condición de ejemplo singular, propone y cumple una cierta regla que podría ser repetida si no fuese porque se da de nuevo cada vez que se da. Como en una danza.

¿Cuál es esta regla?

La de ser lugar.

21 “1. m. Modelo: Arquetipo o punto de referencia para imitarlo o reproducirlo", DRALE.

22 " 2 . m. Modelo: En las obras de ingenio y en las acciones morales, ejemplar que por su perfección se debe seguir e imitar", DRALE. 

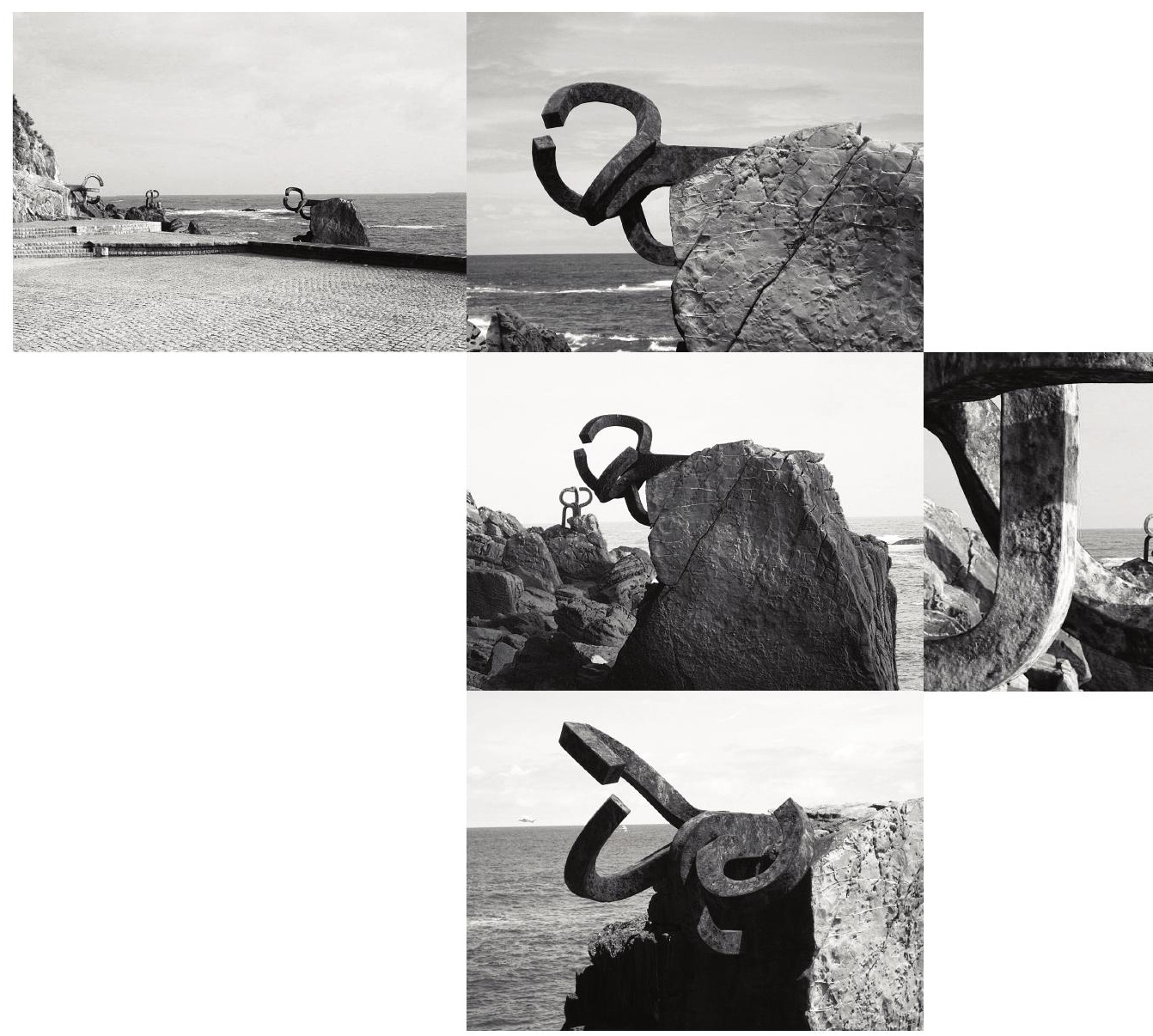


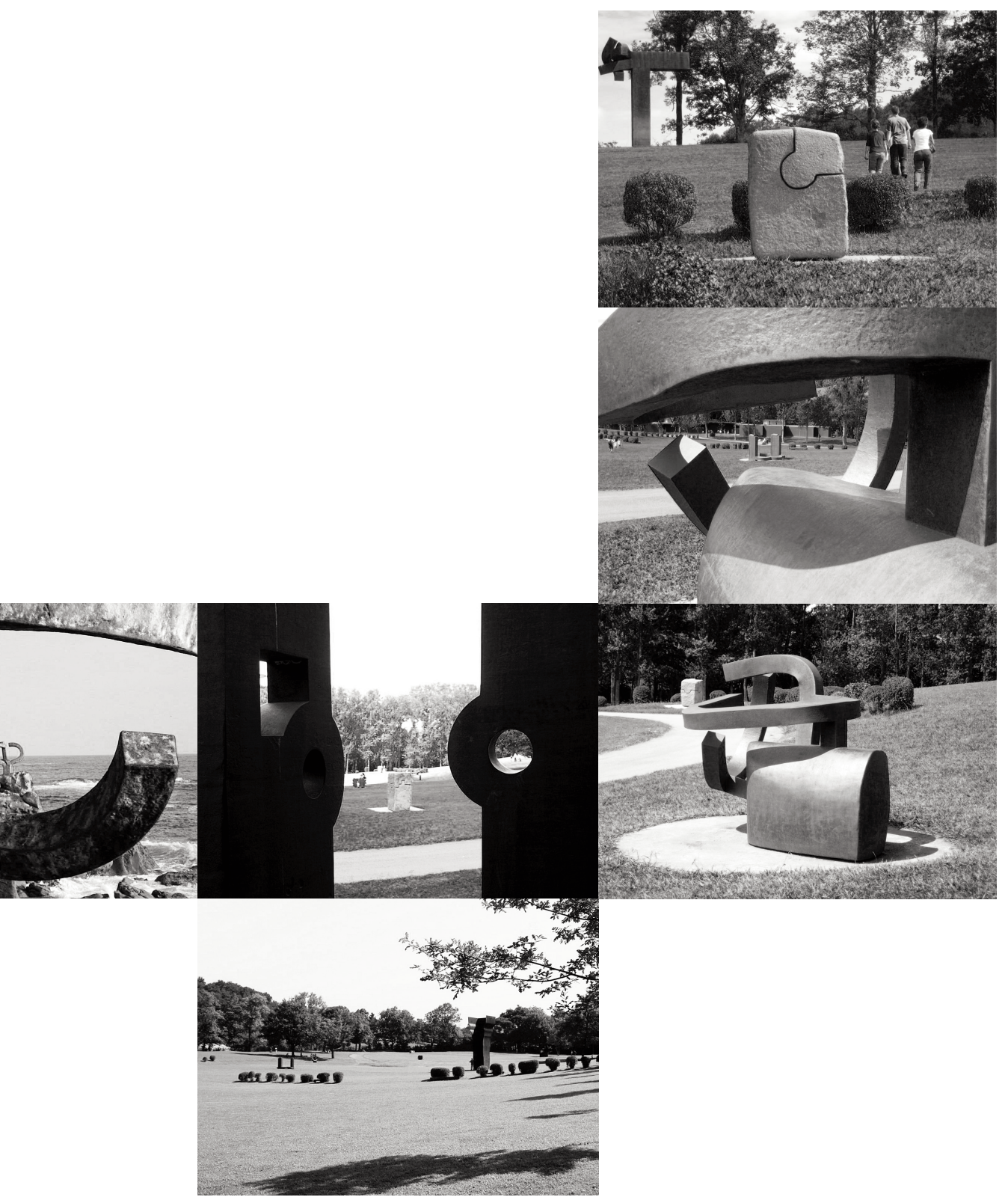




\section{EI lugar como paradigma. De Igueldo a Zabalaga / Igeldotik Zabalagara}

La aparición de esto que antes no estaba, el hacer visible (y posible) la construcción artística en el espacio, transforma éste en un lugar, o por mejor decir, da un lugar, da lugar, se da en el lugar y como lugar: el modelo une en el momento de darse universal y particular, en una relación de singularidad de partes entre partes. Y lo que aparece no estaba antes de la escultura, o lo estaba solo como el aroma de un porvenir:

La forma al principio es un aroma indefinido que se impone en la medida en que va precisándose" ${ }^{\prime 23}$.

Es importante darse cuenta de lo paradójico de la formulación de Eduardo Chillida: el aroma, que necesariamente viene del pasado, que nos llega a través del espacio como un acontecimiento que ya ha tenido lugar (pero no de otra forma toda percepción: ¿qué es mirar una estrella sino contemplar el pasado?) es precisamente la pre-visión del futuro: la visión anticipada de aquello como ya acabado, como un cierto pasado, abre el porvenir a lo que vendrá. Pues, dice Chillida, "uno no debe olvidar que el futuro y el pasado son contemporáneos"24.

Apenas seis kilómetros y medio, diez minutos en coche separan el Peine del viento (número XV), a las faldas del monte Igueldo, del caserío Zabalaga en Hernani, en cuyo jardín se encuentran el Peine del viento número XVII y el XIX. Y es precisamente en Hernani, en la forja de Manuel Illarramendi en $1951^{25}$ donde Chillida comienza a trabajar el hierro, material base de todos los peines. La serie comienza en 1952, con una primera versión que se conserva actualmente en el Museo Reina Sofía, de trazos angulares y rectos, planos elementales que conforman un cierto espacio mediante el despliegue y la soldadura de unas chapas de hierro. El siguiente ejemplar se forja en 1959, y adopta unas formas más blandas, que parecen surgir de un tronco común, en la estela de varias obras anteriores ejecutadas en hierro forjado y que parecen remitir a antiguos aperos de labranza (de hecho su material base, el hierro, Chillida lo busca en las chatarrerías, en los restos procedentes de estos instrumentos agrícolas, y de barandillas de balcones y rejas desechadas, testigos mudos de una

${ }^{23}$ Chillida 2005, op. cit. (nota 3), p. 77. Y también, precisa: "Este preconocimiento o aroma es mi guía en lo desconocido, en lo deseado, en lo necesario" (Ibidem, p. 16).

${ }^{24}$ Ugarte L., Chillida: dudas y preguntas, Donostia-San Sebastián, Erein, 2000, p. 105.

${ }^{25}$ Elósegui Itxaso, M., El Peine del viento de Chillida en San Sebastian. Ingeniería de su colocación por José María Elósegui (1977), Bilbao, Colegio de Ingenieros de Caminos, Canales y Puertos del País Vasco, 2008, p. 27. 
cultura que desaparece). Estas dos primeras tentativas parecen abrir el abanico formal y técnico que dará lugar a la serie completa de peines.

La obra que podemos ver actualmente al final del paseo que bordea la playa de Ondarreta, tras un largo proceso iniciado en 1965 se acabó de colocar el 3 de septiembre de 1977. Tres esculturas, conformando una especie de constelación, se anclan en la roca entre el agua y la tierra, en un emplazamiento que parece hecho para ellas antes que al revés, y de este modo el conjunto semeja haber sido así y ahí desde siempre. Sin embargo, y a pesar de la larga génesis del proyecto, no es hasta 1974, con los Estudios de peine del viento IX a XI, cuando empieza a tomar forma el modelo definitivo, que se define finalmente a lo largo de 1977. Por otro lado, la última propuesta de la larga serie es de 1999, numerada con la cifra XX. El arco temporal cubre, de esta manera, prácticamente toda la carrera del escultor, desde su vuelta desde París en 1951 a su fallecimiento en 2002, pero sin embargo un arco espacial mínimo. Las tres esculturas colocadas al fondo de la plazoleta diseñada por el arquitecto Peña Ganchegui, definen un límite y lo hacen visible, deslindan una línea, la del horizonte, establecen unas nuevas reglas para su comprensión, proponen una nueva medida de los elementos que allí se presentan (agua, tierra, aire, fuego), dan lugar al lugar. Un lugar que antes no era sino un cierto resto, olvidado espacio sin cualificar, se da ahora como espacio con sentido, lugar pleno de apertura, mostración clara de lo que en realidad ahí se da. Y apertura al universo.

Por otra parte, el parque que rodea al caserío Zabalaga configura, junto a éste, un lugar muy especial, el lugar de Chillida, el Chillida-Leku. En este lugar Chillida trabajará, como es conocido, desde principios de la década de 1980, en que visitó la finca por vez primera. A lo largo del parque se disponen, en una estructura cambiante (hay esculturas que han modificado su lugar, que se han trasladado a otros destinos, otras nuevas han aparecido), un conjunto de múltiples piezas que establecen unas relaciones particulares y muy estudiadas entre ellas. El conjunto de parque y caserío constituyen por derecho propio, en su gran escala, un nuevo lugar: ya no es la escultura singular, el paradigma único, sino una multiplicidad que propone una ejemplaridad nueva. Y lo que es más importante: esta red o pauta o regla y modelo que establecen entre sí las esculturas con el sitio para desvelar un lugar se da como una relación cambiante, tanto en la ubicación de las propias esculturas como en el necesario caminar entre ellas del visitante que las hace visibles. Densa red de infinitas reglas-relaciones, que se ajustan en cada momento, en cada instante, en cada cambio atmosférico, en cada nueva percepción de un nuevo visitante, el conjunto se ofrece al descubrimiento tanto como al recuerdo. Como una constelación en constante reaparición, el paradigma es siempre el mismo y es siempre distinto. 
La pregunta, ahora, se amplía. Ya no es una escultura la que se propone como modelo, como paradigma que hace surgir el lugar. Es la relación entre distintas esculturas la que se formaliza en su condición paradigmática. De la forma más evidente, es entre las tres esculturas al borde del mar que surge, con plenitud, un nuevo lugar. Y es en el recorrido a que obliga el jardín del Chillida-Leku que se trazan las líneas que modelan el nuevo lugar. Es, de alguna manera, en la condición obligada de su extensión en el sitio que se muestra con mayor evidencia su condición ejemplar. Y ello sin perder cada escultura un ápice de su propia singularidad, sino tejiendo entre ellas un nuevo lugar. Un lugar del lugar.

Sin añadir ni quitar nada, la regla y el modelo se esconden en el secreto del lugar tanto como se dan en la pr(e)sencia de la obra. La escultura de Eduardo Chillida queda, así, como el guardián de un secreto que, indefectiblemente, permanecerá desconocido estando, sin embargo, y por ello mismo, a la vista de todo el mundo. Hay, pues, lugar. Se da el lugar.

Regalo y don de la escultura. 